\title{
ANALISIS TEKSTUR DAN WARNA CITRA VULVA SAPI UNTUK DETEKSI MASA KAWIN SAPI MENGGUNAKAN LEARNING VECTOR QUANTIZATION
}

\author{
Aminatul Mukarromah ${ }^{1}$, Agus Mulyono ${ }^{2}$ \\ ${ }^{1,2}$ Jurusan Fisika, Universitas Islam Negeri Maulana Malik Ibrahim Malang \\ Jl. Gajayana No. 50 Malang 65144
}

\begin{abstract}
ABSTRAK
Tingkat produksi susu sapi perah di Indonesia lebih rendah daripada tingkat konsumsi susu sapi perah. Sehingga perlu secara professional pengembangan peternakan sapi perah termasuk pembibitannya. Secara umum permasalahan pembibitan sapi adalah kegagalam bunting, dan $70 \%$ penyebab kegagalan kebuntingan sapi adalah deteksi birahi (estrus) yang tidak tepat. Penelitian ini bertujuan untuk mebuat aplikasi deteksi siklus estrus sapi menggunakan learning vector quantization (LVQ), dan untuk mengetahui akurasi keberhasilan metode LVQ dalam mendeteksi siklus estrus sapi. Data yang digunakan dalam penelitian ini adalah nilai suhu dan cirri dari citra vulva sapi estrus, metestrus, diestrus, dan proestrus. Tahapan penelitian ini meliputi: pengukuran suhu vulva sapi, pengambilan citra vulva sapi, analisis tekstur dan warna citra vulva sapi, dan klasifikasi citra vulva sapi. Dari hasil penelitian menunjukkan bahwa metode LVQ tidak dapat mengenali citra vulva sapi metestrus dengan akurasi keberhasilan 0\%. Akan tetapi metode LVQ dapat digunakan untuk mengklasifikasi citra vulva sapi estrus, diestrus, proestrus, dengan akurasi keberhasilan estrus $100 \%$, diestrus $100 \%$, proestrus $60 \%$.
\end{abstract}

Kata Kunci: Siklus Estrus Sapi; Analisis Tekstur Dan Warna; Learning Vector Quantization;

\begin{abstract}
The increasing of milk production of cattle in Indonesia is still lower when it is compared with the needs of the national milk consumption. Around $70 \%$ of the failure cause of pregnant cows is the fault of estrus detection. This research aimed to make a detectin estrus cycle of cattle using learning vector quantization (LVQ), and to know the level of the success of the cattle's estrus cycle detection using LVQ. The data esud in this research are temperature values and vulva image of estrus, metestrus, diestrus, and proestrus. The step of this research temperature measurement of vulva cattles, taking vulva image of cattle, analyzing the tekstur dan colour vulva imeage of cattles and classifying the vulva image of cattles. From the overall findings showed that LVQ method can't recognize the vulva image of metestrus catlle with the accuracy of success is $0 \%$. But, LVQ method can use to classify the image of estrus cattle, dieatrus, and proestrus, with the accuracy of success of estrus until $100 \%$, diestrus $100 \%$, proestrus $60 \%$.
\end{abstract}

Keyword: Estrus Cycle of Cattle; Texture and Color Image Analysis; Learning Vector Quantization;

\section{PENDAHULUAN}

Indonesia merupakan salah satu negara yang mempunyai penduduk yang sangat besar, dimana setiap tahun selalu mengalami peningkatan. Meningkatnya jumlah penduduk akan menyebabkan kebutuhan konsumsi dalam negara juga meningkat. Salah satu kebutuhan konsumsi masyarakat Indonesia adalah susu sapi perah. Menurut data Direktorat Jenderal Peternakan, jumlah konsumsi susu sapi perah di Indonesia dari tahun 
2006-2012 selalu mengalami peningkatan dengan rata-rata peningkatan setiap tahunnya sebesar 13,73\%. Peningkatan jumlah konsumsi susu sapi perah ini dibarengi dengan peningkatan produksi susu sapi perah dengan rata-rata peningkatan setiap tahunnya sebesar 7,92\%. Perbedaan peningkatan konsumsi dengan produksi susu sapi perah ini sangatlah tinggi sehingga kebutuhan akan susu sapi perah di Indonesia masih belum terpenuhi. Hal ini menyebabkan Indonesia melakukan kebijakan impor susu sapi dari luar Negeri. Jika impor susu sapi ini berkelanjutan maka akan berdampak terhadap harga susu sapi domestik dan secara otomatis akan menguras devisa Negara dengan jumlah yang sangat besar. Oleh karena itu perlu dilakukan pengembangan perkembangbiakan sapi perah di Indonesia (1).

Langkah pertama dalam mengembangan perkembangbiakan sapi adalah mencari factor penyebab kegagalan kebuntingan sapi perah. Berdasarkan survey yang dilakukan Badan Pengkajian Teknologi Pertanian (BPTP), 70\% penyebab kegagalan sapi bunting adalah akibat deteksi birahi (estrus) yang dilakukan peternak tidak tepat, sehingga dapat dikatakan bahwa mengenal tanda sapi estrus merupakan kunci keberhasilan kebuntingan sapi. Tanda-tanda sapi estrus dapat dilihat secara fisik, yaitu warna vulva sapi memerah, membengkak, dan hangat. Selain mengamati tanda-tanda tersebut, dokter hewan juga melakukan palpasi rektal dengan memasukkan tangan ke dalam rektum sapi untuk memastikan bahwa sapi benar-benar berada pada fase estrus yang kemudian sapi akan dikawinkan. Metode palpasi rektal dalam agama Islam dirasa kurang mencerminkan rasa kasih sayang terhadap seluruh alam, termasuk hewan.

Proestrus merupakan fase sebelum estrus. Pada fase ini, ,folikel de graaf bertumbuh di atas pengaruh follicle stimulating hormone (FSH). Estrus merupakan fase dimana sapi betina siap menerima sapi jantan untuk kopulasi. Selama fase estrus, folikel de graff menjadi matang dan membesar, estradiol yang dihasilkan folikel de graff akan menyebabkan perubahan-perubahan pada saluran reproduksi yang maksimal. Metestrus merupakan fase terjadinya ovulasi. Metestrus sebagian besar berada di bawah pengaruh hormon progesterone yang dihasilkan oleh korpus luteum. Selanjutnya pada fase diestrus corpus luteum menjadi matang dan pengaruh progesteron terhadap saluran reproduksi menjadi nyata. Pada fase ini corpus luteum berkembang dengan sempurna dan efek yang dihasilkan dari progesteron (hormon yang dihasilkan oleh corpus luteum) tampak dengan jelas pada dinding uterus. Corpus luteum ini tetap sampai hari ke 17 atau 18 dari siklus estrus (2).

Tamam (2011) dalam mendeteksi estrus sapi menggunakan filter gabor dan analisis warna terhadap citra vulva sapi menggunakan jaringan syaraf tiruan backpropagation menunjukkan bahwa metode backpropagation memberikan tingkat keberhasilan 80\% dalam mengenali citra vulva sapi estrus dan diestrus. Untuk memperoleh tingkat keberhasilan yang lebih tinggi maka dibutuhkan metode lain yang lebih baik dari backpropagation (3).

Nurkhozin, dkk (2011) mengkomparasi klasifikasi penyakit diabetes milletus menggunakan jaringan syaraf tiruan backpropagation dan learning vector quantization. Hasil penelitian tersebut menunjukkan bahwa metode learning vector quantization lebih akurat dibandingkan dengan backpropagation. Oleh karena itu pada penelitian ini 
digunakan metode learning vector quantization (LVQ) untuk mendeteksi siklus estrus sapi (4).

Metode LVQ menggunakan vector acuan (vector reference) dari satu unit keluaran yang menjadi acuan bagi kelas/ kategori yang mewakili oleh keluaran tersebut. Pendekatan yang dilakukan adalah mengelompokkan vektor input berdasarkan kedekatan jarak vektor input terhadap bobot (metode kuadrat jarak euclidean minimum). Learning Vector Quantization merupakan salah satu metode jaringan saraf tiruan yang berbasis kompetisi dengan mekanisme squared euclidien distance dalam memilih vektor pewakil pemenang untuk menentukan kategori vektor masukan. Proses pembelajaran LVQ merupakan pembelajaran supervised atau dengan kata lain menggunakan pengarahan, dengan tujuan untuk mendapatkan vektor-vektor pewakil yang akan melakukan kuantisasi terhadap vektor masukan (5).

Tujuan penelitian ini adalah untuk mendapatkan metode baru yang lebih humanis terhadap hewan untuk mendeteksi siklus estrus sapi menggunakan learning vector quantization (LVQ), dan untuk mengetahui akurasi keberhasilan metode LVQ dalam mendeteksi siklus estrus sapi.

\section{METODE PENELITIAN}

Penelitian ini bertujuan untuk membangun suatu perangkat lunak menggunakan jaringan syaraf tiruan learning vector quantization yang dapat digunakan untuk membantu mengidentifikasi siklus estrus sapi. Untuk mewujudkannya dibuatlah rancangan penelitian sebagai berikut:

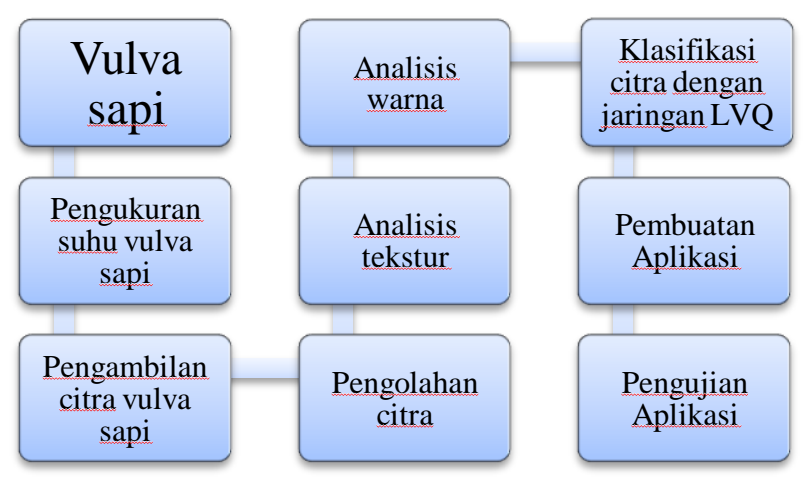

Gambar 1. Rancangan Penelitian

Alat dan bahan yang digunakan pada penelitian ini antara lain kamera digital Pentax 14 megapixel, termometer digital, alat bantu pengambilan citra vulva sapi, PC dengan software matlab, 15 citra vulva sapi proestrus, 15 citra vulva sapi estrus, 15 citra vulva sapi metsetrus, dan 15 citra vulva sapi diestrus.

Tahapan pengumpulan data penelitian dibagi menjadi 3, yaitu pengukuran suhu vulva sapi yang dilakukan per vaginal dengan memasukkan ujung termometer selama 1-3 menit, pengambilan citra vulva sapi estrus, metestrus, diestrus, proestrus, dan pengolahan citra untuk menentukan karakteristik citra vulva sapi dengan menggunakan analisis tekstur dan warna. Setelah dilakukan tahapan tersebut, maka diperoleh data hasil penelitian yang mencakup nilai suhu vulva sapi, nilai mean, skewness, variance, kurtosis, dan entropy yang 
dihasilkan dari analisis tekstur citra vulva sapi, dan nilai pixel red, green, blue yang dihasilkan dari analisis warna citra vulva sapi. Data-data tersebut kemudian dijadikan sebagai inputan pada jaringan learning vector quantization (LVQ).

Klasifikasi citra vulva sapi dengan jaringan LVQ melibatkan 2 proses utama, yaitu pembelajaran dan pengujian. Pembelajaran merupakan proses dimana jaringan LVQ dilatih menggunakan data pola-pola tertentu smpai LVQ dapat mengenali pola tersebut. Data pembelajaran yang digunakan dalam penelitian ini adalah 40 data yang mewakili data vulva sapi estrus, metestrus, diestrus, proestrus. Parameter-parameter yang digunakan pada metode LVQ ini adalah sebagai berikut:

1. Alfa (Learning rate)

Alfa didefinisikan sebagai tingkat pembelajaran. Jika alfa terlalu besar, maka algoritma akan menjadi tidak stabil sebaliknya jika alfa terlalu kecil, maka prosesnya akan terlalu lama. Nilai alfa adalah $0<\alpha<1$.

2. DecAlfa (Penurunan Learning rate)

Yaitu penurunan tingkat pembelajaran.

3. MinAlfa (Minimum Learning rate)

Yaitu minimal nilai tingkat pembelajaran yang masih diperbolehkan.

4. MaxEpoch (Maksimum epoch)

Yaitu jumlah epoch atau iterasi maksimum yang boleh dilakukan selama pelatihan.

Iterasi akan dihentikan jika nilai epoch melebihi epoch maksimum.

Algoritma proses pembelajaran pada metode LVQ disajikan pada Gambar 3.

Setelah dilakukan pelatihan, akan diperoleh bobot-bobot akhir (w). Bobot-bobot ini selanjutnya digunakan untuk melakukan proses pengujian. Algoritma proses pengujian pada jaringan LVQ disajikan pada gambar 2.

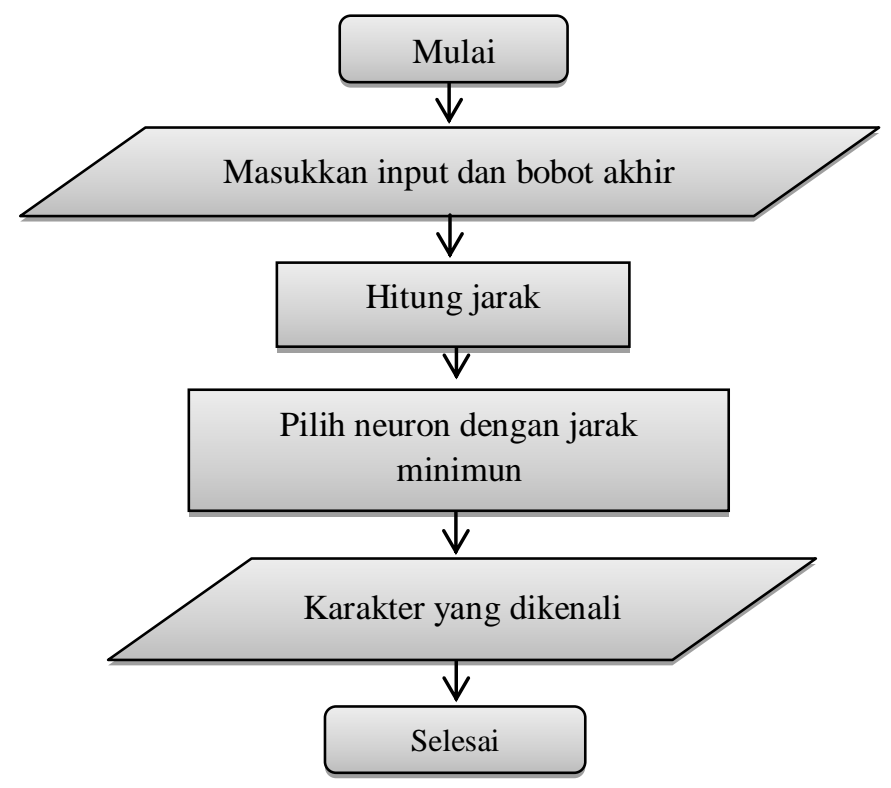

Gambar 2. Algoritma Pengujian LVQ

Algoritma pengujian tersebut kemudian dibuat menjadi aplikasi pendeteksi siklus estrus dengan menggunakanGraphical User Interface(GUI) pada MATLAB 7.1. 


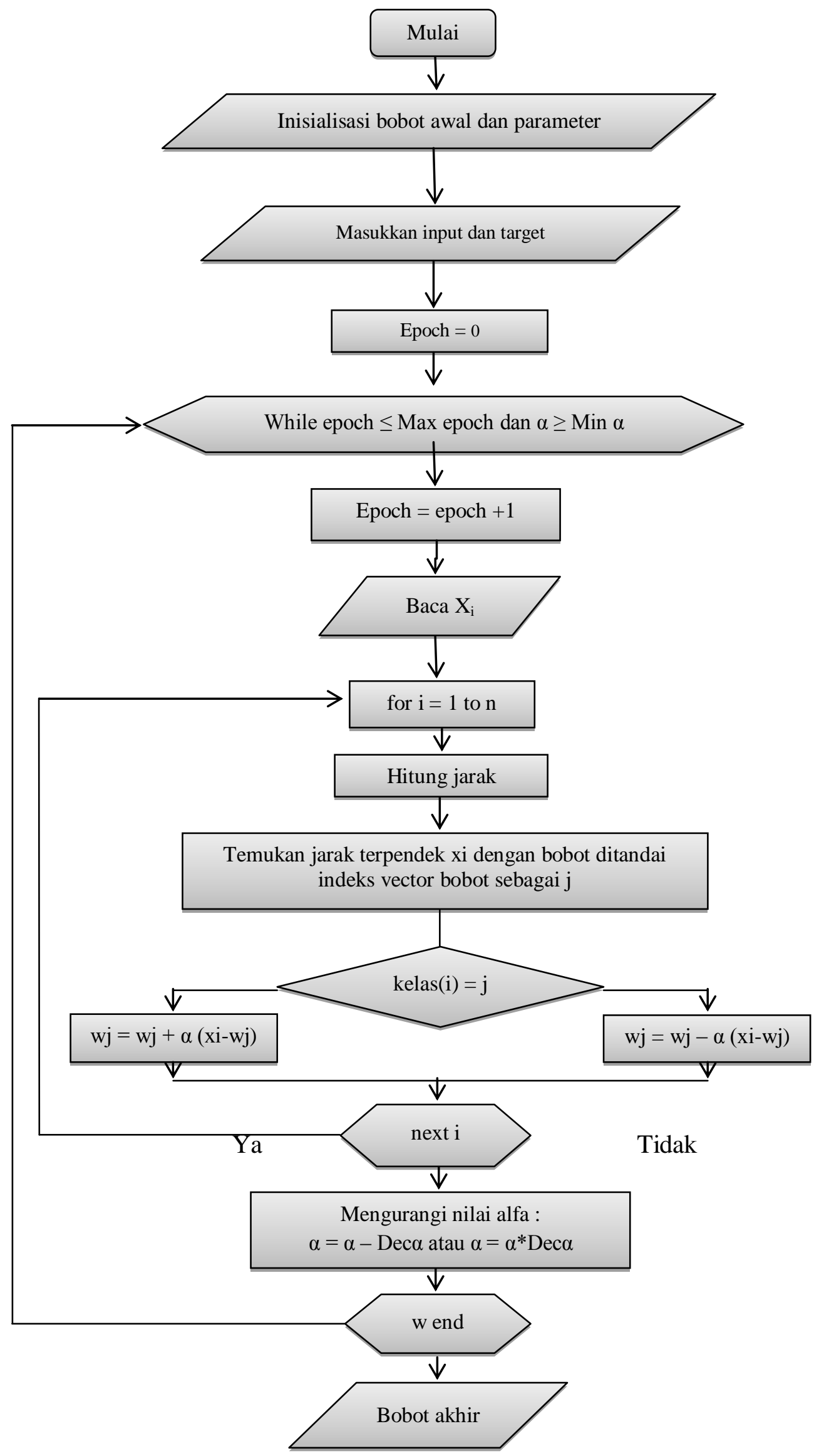

Gambar 3. Algoritma Pembelajaran LVQ 


\section{HASIL DAN PEMBAHASAN}

LVQ melakukan pembelajaran pada lapisan kompetitif yang terawasi. Suatu lapisan kompetitif akan secara otomatis belajar untuk mengklasifikasikan vektor-vektor input. Kelas-kelas yang didapatkan sebagai hasil dari lapisan kompetitif ini hanya tergantung pada jarak antara vektor input dengan vektor bobot dari masing-masing kelas dan vektor input akan masuk ke dalam kelas yang memiliki jarak terdekat. Algoritma pembelajaran pada LVQ bertujuan mencari nilai bobot yang sesuai untuk mengelompokkan vektorvektor input ke dalam kelas yang sesuai dengan yang telah diinisialisasi pada saat pembentukan jaringan LVQ. Variabel masukan yang digunakan dalam penelitian ini dapat dilihat pada tablel 1 .

Tabel 1. Variabel Masukan

\begin{tabular}{cc}
\hline Variabel & Satuan Nilai \\
\hline $\mathrm{X}_{1}$ & Suhu \\
$\mathrm{X}_{2}$ & Mean \\
$\mathrm{X}_{3}$ & Entropy \\
$\mathrm{X}_{4}$ & Variance \\
$\mathrm{X}_{5}$ & Skewness \\
$\mathrm{X}_{6}$ & Kurtosis \\
$\mathrm{X}_{7}$ & Red \\
$\mathrm{X}_{8}$ & Green \\
$\mathrm{X}_{9}$ & Blue \\
\hline
\end{tabular}

Pada perhitungan jarak euclidean, atribut yang berskala panjang dapat mempunyai pengaruh lebih besar daripada atribut berskala pendek. Oleh sebab itu, untuk mencegah hal tersebut perlu dilakukan normalisasi terhadap nilai atribut yakni proses transformasi nilai menjadi kisaran 0 dan 1 . Salah satu metode normalisasi adalah min-max normalization yang diterapkan untuk setiap variabel masukan. Persamaan untuk normalisasi adalah:

$$
\mathrm{X}^{*}=\frac{X-\operatorname{Min}(X)}{\operatorname{Max}(X)-\operatorname{Min}(X)}
$$

dengan,

$\mathrm{X}^{*}=$ nilai setelah dinormalisasi

Min $(\mathrm{x})=$ nilai minimum dari seluruh data dalam kelas tertentu

$\operatorname{Max}(\mathrm{x})=$ nilai maximum dari seluruh data dalam kelas tertentu

Arsitektur jaringan LVQ yang akan dibangun terdiri dari 9 input dan 4 output. Variabel output yang ingin di capai dapat dilihat pada tabel 2.

\begin{tabular}{cc}
\multicolumn{2}{c}{ Tabel 2. Variabel Output } \\
\hline Satuan Nilai & Keterangan \\
\hline 1 & Estrus \\
2 & Metestrus \\
3 & Diestrus \\
4 & Proestrus \\
\hline
\end{tabular}

Berdasarkan variabel masukan dan kelas yang diinginkan, maka arsitektur jaringan yang dibangun dapat dilihat pada gambar 4. 


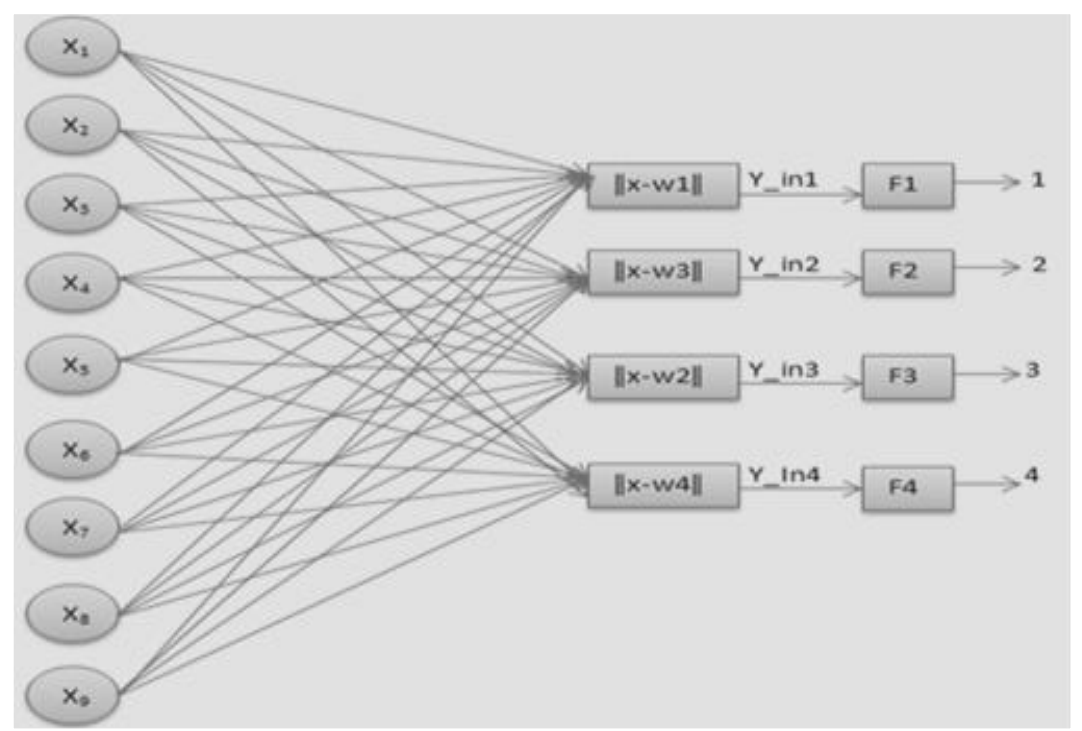

Gambar 4. Arsitektur Jaringan LVQ

Berdasarkan Gambar di atas, tampak bahwa dalam LVQ terdapat 9 vektor bobot yang menghubungkan setiap neuron masukan dengan neuron keluaran sehingga dapat dikatakan bahwa setiap neuron keluaran pada LVQ berhubungan dengan sebuah vektor bobot. Pada proses pengenalan dan pembelajaran, LVQ menggunakan operasi-operasi vektor. Pola-pola akan disajikan dalam bentuk vektor. Proses yang terjadi pada setiap neuron adalah mencari jarak antara suatu vektor input ke bobot yang bersangkutan. Fungsi aktivasi $(F)$ yang digunakan pada arsitektur jaringan LVQ adalah fungsi linier, tujuannya adalah agar diperoleh keluaran yang sama dengan masukan.

LVQ mengklasifikasikan data berdasarkan kedekatan jarak antara suatu vektor masukan ke bobot yang bersangkutan. LVQ memanfaatkan posisi dari suatu titik koordinat $\mathrm{x}$ dan $\mathrm{y}$. Dalam penelitian ini, sumbu $\mathrm{x}$ adalah nilai yang menentukan banyaknya warna red, green, blue dalam citra. Sedangkan sumbu y adalah nilai suhu, mean, entropy, variance, skewness, dan kurtosis. Pola data masukan penelitian ini disajikan pada gambar 5 .

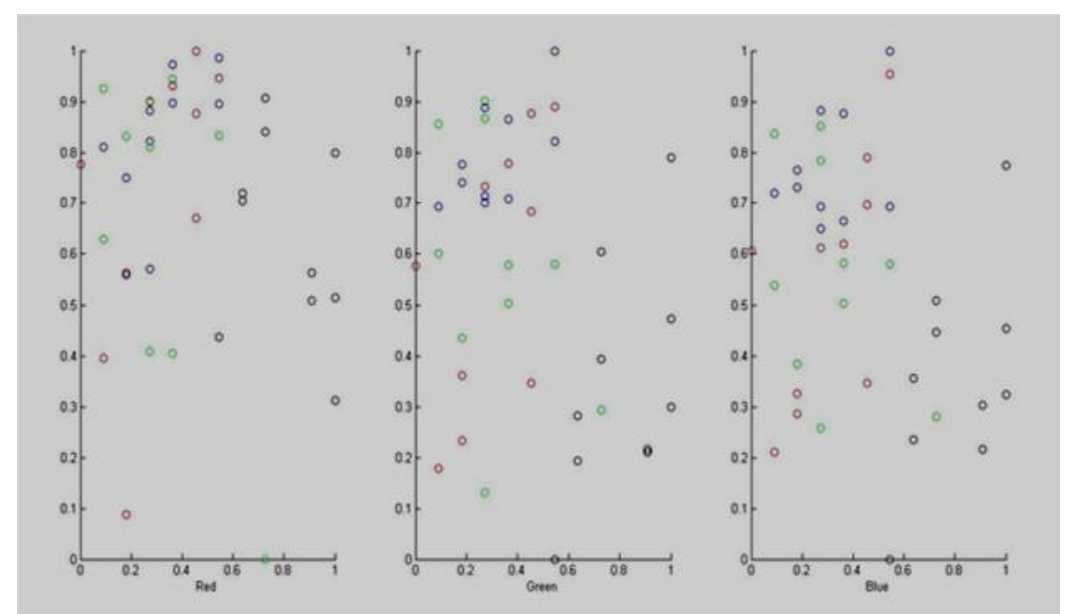

Gambar 5. Pola Data Masukan

Keterangan gambar:

Hitam : estrus 


\section{Biru : diestrus \\ Merah : metestrus \\ Hijau : proestrus}

Berdasarkan gambar pola data masukan dapat diketahui bahwa citra vulva sapi estrus dan diestrus mempunyai karakteristik dan pola yang berbeda, hal ini dapat dilihat pada gambar yang menunjukkan bahwa citra vulva estrus (hitam) terpisah dengan citra vulva diestrus (biru). Sedangkan citra vulva sapi metestrus dan proestrus mempunyai karakteristik dan pola yang mirip, hal ini dapat dilihat pada titik hijau dan titik merah yang berkumpul pada koordinat tertentu. Untuk itu perlu dilakukan pendekatan antara data metestrus dan proestrus. Gambar pola data masukan menunjukkan bahwa data metestrus dan proestrus memiliki pola mirip dengan data diestrus, hal ini dapat dilihat pada titik hijau, merah, dan biru yang cenderung berkumpul pada koordinat tertentu. Oleh karena itu, proses pembelajaran dilakukan dengan beberapa langkah.

Langkah pertama: Memasukkan data diestrus, metestrus, dan proestrus ke dalam satu kelas, yaitu kelas diestrus. Data input yang digunakan sebanyak 40 data yang mewakili kelas estrus, diestrus, metestrus, dan proestrus. Apabila data input masuk ke dalam kelas estrus, maka proses pengenalan selesai. Akan tetapi jika input masuk ke dalam kelas diestrus, maka proses pengenalan akan dilanjutkan pada langkah kedua.

Langkah kedua : Memisahkan data dietrus, metestrus, dan proestrus menjadi 2 kelas. Kelas pertama adalah kelas diestrus, dan kelas kedua adalah gabungan dari data metestrus dan proestrus (met-pro). Data input yang digunakan adalah 30 data yang mewakili kelas diestrus, metestrus, dan proestrus. Apabila data input masuk ke dalam kelas diestrus, maka proses pengenalan selesai. Akan tetapi jika input masuk ke dalam kelas metpro, maka proses pengenalan akan dilanjutkan pada langkah ketiga.

Langkah ketiga : Memisahkan data metestrus dan proestrus menjadi 2 kelas. Kelas pertama adalah kelas metestrus, dan kelas kedua proestrus. Data input yang digunakan adalah 20 data yang mewakili kelas metesrus dan diestrus.

Pada proses pembelajaran, setip bobot awal akan diubah (di-update) tergantung dari kelas vektor masukan sesuai dengan kelas yang dinyatakan sebagai neuron pemenang. Jika sesuai, maka vektor bobot di-update sehingga jaraknya semakin dekat dengan vektor masukan. Jika tidak, vektor bobot di-update sehingga jaraknya semakin jauh dengan vektor masukan tersebut. Kemudian bobot yang dihasilkan dari setiap pembelajaran akan digunakan sebagai bobot baru dalam proses pengujian jaringan.

Tampilan program Matlab untuk klasifikasi citra vulva sapi menggunakan learning vector quantization dapat dilihat pada gambar 6 .

Proses pengujian aplikasi ini menggunakan 20 data baru dengan 5 data estrus, 5 data metestrus, 5 data diestrus, dan 5 data proestrus. Hasil dari pengujian aplikasi deteksi siklus estrus sapi dapat dilihat pada table 2. 
Jurnal Neutrino Vol. 8, No. 1. Oktober 2015

29

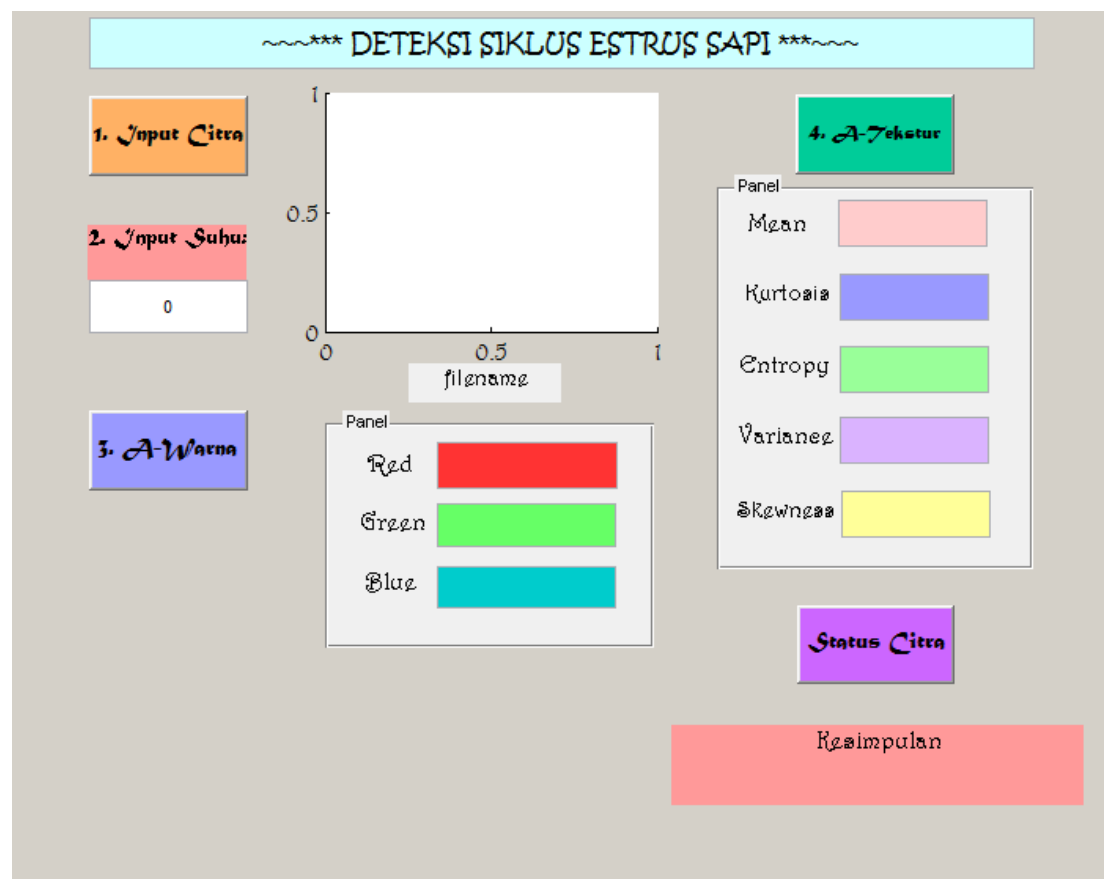

Gambar 6. Aplikasi Deteksi Siklus Estrus Sapi

Tabel 2. Hasil Pengujian Aplikasi

\begin{tabular}{clc}
\hline Data ke- & Target & $\begin{array}{c}\text { Hasil Pengenalan } \\
\text { Jaringan }\end{array}$ \\
\hline 1 & Estrus & Estrus \\
2 & Estrus & Estrus \\
3 & Estrus & Estrus \\
4 & Estrus & Estrus \\
5 & Estrus & Estrus \\
6 & Diestrus & Diestrus \\
7 & Diestrus & Diestrus \\
8 & Diestrus & Diestrus \\
9 & Diestrus & Diestrus \\
10 & Diestrus & Diestrus \\
11 & Metestrus & Proestrus \\
12 & Metestrus & Diestrus \\
13 & Metestrus & Diestrus \\
14 & Metestrus & Diestrus \\
15 & Metestrus & Diestrus \\
16 & Proestrus & Proestrus \\
17 & Proestrus & Proestrus \\
18 & Proestrus & Distrus \\
19 & Proestrus & Estrus \\
\hline 20 & Proestrus & Prostrus \\
\hline & & \\
\hline
\end{tabular}

Berdasarkan pengamatan pada tabel di atas, dapat dilihat bahwa akurasi jaringan LVQ dalam mengenali data estrus dan diestrus mencapai $100 \%$, untuk data proestrus $60 \%$, dan metestrus $0 \%$. 


\section{KESIMPULAN}

Dari hasil penelitian, pengolahan citra, perancangan, pembuatan, dan pengujian sistem pada penelitian ini, didapatkan simpulan bahwa metode learning vector quantization dapat digunakan untuk mendeteksi siklus estrus sapi pada fase estrus, diestrus, dan proestrus dengan akurasi keberhasilan $100 \%$ untuk data estrus dan diestrus, $60 \%$ untuk data proestrus. Akan tetapi metode ini tidak dapat mengenali fase metestrus dengan akurasi keberhasilan $0 \%$.

\section{DAFTAR PUSTAKA}

1. Direktorat Jenderal Peternakan. Buku Statistik Peternakan. Jakarta: Kementerian Pertanian; 2010.

2. Frandson, R. D. Anatomi dan Fisiologi Ternak, Edisi ke-7. diterjemahkan oleh Srigandono, B dan Praseno, K. Yogyakarta: Gadjah Mada University Press; 1996

3. Tamam, Badrit. Deteksi Masa Kawin Sapi Melalui Citra Vulva Menggunakan Jaringan Syaraf Tiruan Backpropagation. Skripsi Tidak Diterbitkan. Malang: Jurusan Fisika. Fakultas Sains dan Teknologi Universitas Islam Negeri (UIN) Maulana MalikIbrahim Malang; 2011.

4. Nurkhozin, A, dkk. Komparasi Hasil Klasifikasi Penyakit Diabetes Mellitus Menggunakan Jaringan Syaraf Tiruan Backpropagation dan Learning Vector Quantization. Prosiding Seminar Nasional Penelitian, Pendidikan dan Penerapan FMIPA UNY; 2011.

5. Kusumadewi S. Artificial Intelegence (Teknik dan Alikasinya).Yogyakarta:Graha Ilmu; 2003. 